\title{
Research on Characteristic and Application of Non- Contact Probe Based on Small Multi-Axis Measurement Machine
}

\author{
Lei Wenming \\ Aviation Key Laboratory of Science and Technology on \\ Precision Manufacturing Technology \\ Beijing Precision Engineering Institute for Aircraft Industry \\ Beijing, China

\section{Li Di} \\ Aviation Key Laboratory of Science and Technology on \\ Precision Manufacturing Technology \\ Beijing Precision Engineering Institute for Aircraft Industry \\ Beijing, China
}

\begin{abstract}
In this paper, theory analysis and experiment validation of probes based on laser triangulation and conoscopic holography were compared. The research was carried out based on small multi-axis measurement machine which was designed for rapid detection of aero-engine components. Standard sphere was measured with two probes and fitted by the least-square method. According to the results and analysis, the probe based on conoscopic holography was selected for dedicating small and complex aero-engine components such as vane and nozzle. The system will offer high speed and high precision for measuring the typical characteristics of components which are very important for aviation industry.
\end{abstract}

Keywords-conoscopic holography, laser triangulation, probe, measure

\section{INTRODUCTION}

In recent years, with the rapid development of manufacture on aero-engine, the measure precision and efficiency become higher for important components on aero-engine such as vane and nozzle. In modern industry, parameters on complex components cannot be easily measured with contact probe as it may destroy the surface and cannot touch some parameters. Facing these requirements, non-contact probe is becoming a hotspot for research and has been used widely now.

On the basis of structured light technology, Gom in German produced an optical scanning measurement system named ATOS which can finish an image within one minute including 430,000 points. 3D SCANNER Co. in England used laser triangulation to produce an optical probe named REVERSE whose scanning speed is 15,000 points per second and the precision is within 10 30 $\mu \mathrm{m}$ [1]. Gao from Tianjin University designed a conoscopic holography system for detecting surface form and the indeterminacy is $5 \mu \mathrm{m}$ [2].

\author{
Wang Lei \\ Aviation Key Laboratory of Science and Technology on \\ Precision Manufacturing Technology \\ Beijing Precision Engineering Institute for Aircraft Industry \\ Beijing, China \\ Fang Jianguo \\ Aviation Key Laboratory of Science and Technology on \\ Precision Manufacturing Technology \\ Beijing Precision Engineering Institute for Aircraft Industry \\ Beijing, China
}

Whatever, not all these non-contact measurements can effectively use on aero-engine nozzle. According to the requirement on the rapid detection of aero-engine nozzle and the existing research condition, in this paper, we first analyzed the basic theory of two non-contact probes on laser triangulation and conoscopic holography, then put them on the dedicated measurement system of aero-engine nozzle for experiment, finally selected the fitter probe to apply. As a result, the dedicated measurement system of aero-engine nozzle will be optimized.

\section{LASER TRIANGULATION}

\section{A. Basic Theory}

Laser Triangulation is a photoelectric detecting technology. It can be divided into point-blank and oblique. And it has advantages of simple structure, high detecting speed, strong real-time processing ability, flexible and convenient use [3]. Using this method to measure curve, the angle it can reach is $\pm 40^{\circ}$, but the best surface roughness is between $1.6 \sim 12.5 \mu \mathrm{m}$.

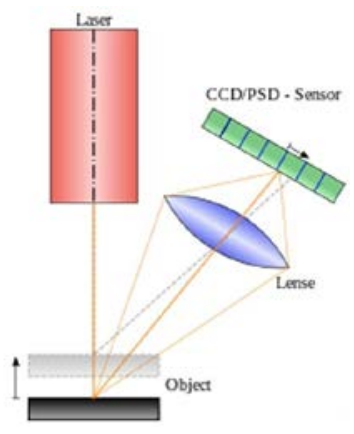

Fig. 1. Laser Triangulation

Taking the point-blank as an example shown in Fig.1, when the light from the lamp-house arrives at the object to measure, 
it will be reflected and finally image on the detector. When place of the object changes, the image on the detector will occur a corresponding displacement. This displacement can be written as:

$$
\delta=\frac{\mathrm{d} \cdot \mathrm{s} \cdot \sin \beta}{\mathrm{s}^{\prime} \cdot \sin \alpha-\mathrm{d} \cdot \sin (\alpha+\beta)}
$$

where $\mathrm{d}$ is the displacement of imaging point on the sensor, $\alpha$ is the angle between the projection axis and the imaging object lens axis, $\beta$ is the angle between receive face on the detector and the imaging object lens axis, $s$ is the object distance and $\mathrm{s}^{\prime}$ is the image distance.

\section{B. Linearity Test}

We test the linearity by taking points when the angle between the object and the $\mathrm{Y}$ axis is $0^{\circ}, 10^{\circ}, 20^{\circ}, 30^{\circ}$ and $41^{\circ}$ before and after the probe has been calibrated. The results of $0^{\circ}$ and $41^{\circ}$ for typical examples are shown in Fig.2.

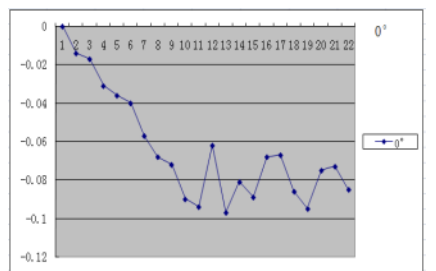

(a) $0^{\circ}$ before calibration

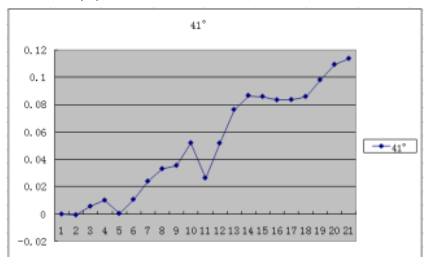

(c) $41^{\circ}$ before calibration

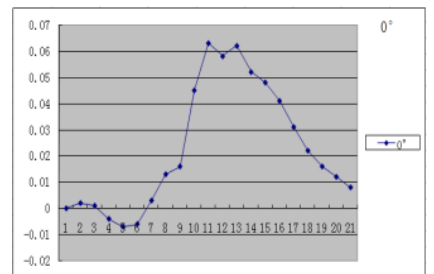

(b) $0^{\circ}$ after calibration

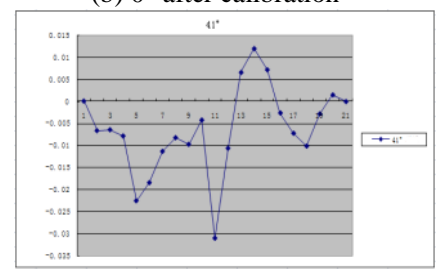

(d) $41^{\circ}$ after calibration
Fig. 2. Result of linearity test on laser triangulation probe

\section{Repeatability Precision Test}

We test the repeatability precision by taking points when the angle between the object and the $\mathrm{Y}$ axis of the dedicated measurement system of aero-engine nozzle is $0^{\circ}$ and $10^{\circ}$ before the probe has been calibrated. Keep the $\mathrm{Y}$ axis move from $65 \mathrm{~mm}$ to $105 \mathrm{~mm}$ by $2 \mathrm{~mm}$ per step for two times and the results are shown in Fig.3.

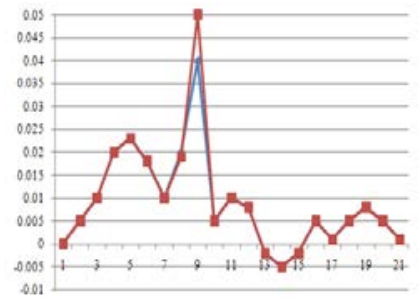

(a) result of $0^{\circ}$

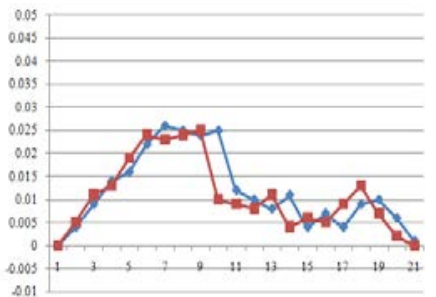

(b) result of $10^{\circ}$
Fig. 3. Result of repeatability precision test on laser triangulation probe

\section{CONOSCOPIC HOLOGRAPHY}

\section{A. Basic Theory}

Conoscopic Holography was firstly put forward by G.Y.Sirat and D.Psaltis of California Institute of Technology in
1985, and is used widely now after years of development and breakthrough [4, 5]. The Optimet Co. in Israel produced two kinds of probe conoprobe and conoline based on conoscopic holography. The inside structure of conoprobe is shown in Fig.4.

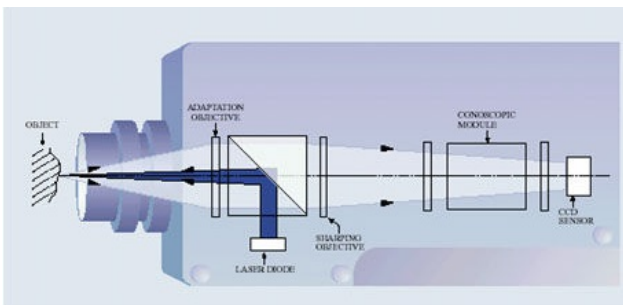

Fig. 4. The inside structure of conoprobe

The light reflected by the surface of object to measured goes through the polarizer and become a polarizable light, then it goes through the uniaxial crystal and divides into ordinary light and extraordinary light whose speed is different. These two lights interfere on the Gabor mirror, and we can get the hologram of interference. The intensity of interference fringe can be written as:

$$
I(\rho)=I_{0}\left[1+\cos \left(K \frac{r^{2}}{Z_{c}^{2}}\right)\right]
$$

Where $\mathrm{K}$ is the wave number, $\mathrm{I}_{0}$ is the intensity of incident light, $Z_{c}$ is the distance between the point to measured and origin of coordinate, $r$ is the distance between one point and the Gabor mirror center.

Using this method to measure curve, the precision is $0.5 \mu \mathrm{m}$ and the scanning frequency is $10 \mathrm{KHz}$ with advantages such as excellent interference immunity, stability, high efficiency and surface characteristic avoidance.

\section{B. Indeterminacy Test}

Keep the light from the probe and the $\mathrm{Z}$ axis is parallel. Lay a standard block on the worktable, seesaw the $\mathrm{Z}$ axis and adjust the indicating value of the probe nearby zero and adjust the raster of $\mathrm{Z}$ axis to zero, record the indicating value of the probe as c, then keep the $Z$ axis move from $0 \mathrm{~mm}$ to $0.62 \mathrm{~mm}$ by $20 \mu \mathrm{m}$ per step and record each indicating value of the probe and the raster as $l_{i}$ and $g_{i}$. The error $e_{i}$ can be written as:

$$
\mathrm{e}_{\mathrm{i}}=\mathrm{l}_{\mathrm{i}}-\mathrm{g}_{\mathrm{i}}-\mathrm{C}
$$

The data is shown in TABLE I. 
TABLE I. DATA OF INDETERMINACY EXPERIMENT

\begin{tabular}{|c|c|c|c|}
\hline Number & $\mathrm{g}_{\mathrm{i}} / \mu \mathrm{m}$ & $\mathrm{l}_{\mathrm{i}} / \mu \mathrm{m}$ & $\mathbf{e}_{\mathrm{i}} / \mu \mathrm{m}$ \\
\hline 1 & 0 & 1.32 & 0.11 \\
\hline 2 & -20.39 & 21.60 & 0.01 \\
\hline 3 & -40.49 & 42.03 & 0.33 \\
\hline 4 & -60.05 & 61.88 & 0.62 \\
\hline 5 & -80.31 & 82.31 & 0.80 \\
\hline 6 & -100.06 & 101.80 & 0.53 \\
\hline 7 & -120.15 & 121.49 & 0.14 \\
\hline 8 & -140.06 & 141.55 & 0.28 \\
\hline 9 & -160.11 & 161.52 & 0.21 \\
\hline 10 & -180.19 & 181.40 & 0.01 \\
\hline 11 & -200.06 & 201.62 & 0.35 \\
\hline 12 & -220.12 & 221.90 & 0.58 \\
\hline 13 & -240.46 & 241.74 & 0.07 \\
\hline 14 & -260.19 & 262.08 & 0.69 \\
\hline 15 & -280.25 & 282.32 & 0.87 \\
\hline 16 & -300.04 & 301.88 & 0.64 \\
\hline 17 & -320.01 & 321.91 & 0.70 \\
\hline 18 & -340.07 & 341.49 & 0.21 \\
\hline 19 & -360.42 & 361.79 & 0.17 \\
\hline 20 & -380.43 & 381.87 & 0.23 \\
\hline 21 & -400.09 & 401.93 & 0.64 \\
\hline 22 & -420.49 & 422.57 & 0.87 \\
\hline 23 & -440.35 & 442.12 & 0.57 \\
\hline 24 & -460.43 & 462.12 & 0.49 \\
\hline 25 & -480.23 & 482.20 & 0.76 \\
\hline 26 & -500.24 & 502.16 & 0.72 \\
\hline 27 & -520.14 & 521.94 & 0.60 \\
\hline 28 & -540.03 & 541.83 & 0.60 \\
\hline 29 & -560.13 & 562.06 & 0.73 \\
\hline 30 & -580.09 & 582.16 & 0.87 \\
\hline 31 & -600.45 & 602.09 & 0.43 \\
\hline
\end{tabular}

During the experiment, $\mathrm{c}=1.32 \mu \mathrm{m}$, after calculation we can get the standard deviation of $\mathrm{e}_{\mathrm{i}}$ is $0.27 \mu \mathrm{m}$, according to the three-sigma principle of normal distribution, the indeterminacy will be $0.81 \mu \mathrm{m}$.

\section{Angle Range Test}

Keep the probe stay in the origin, measure the max circle on the standard sphere, and analyze the deviation of different central angle and corresponding point. To measure the arc, firstly we need to find the apogee of the standard sphere. Diameter of the sphere we used is $12 \mathrm{~mm}$, and the form is less than $0.05 \mu \mathrm{m}$.

Suppose $\left(\mathrm{x}_{\mathrm{i}}, \mathrm{z}_{\mathrm{i}}\right)$ is the point coordinate of the arc and $\left(\mathrm{x}_{0}, \mathrm{z}_{0}\right)$ is the origin coordinate, then the deviation between the normal arc and the actual arc can be written as:

$$
\Delta \mathrm{r}_{\mathrm{i}}=\sqrt{\left(\mathrm{x}_{\mathrm{i}}-\mathrm{x}_{0}\right)^{2}+\left(\mathrm{z}_{\mathrm{i}}-\mathrm{z}_{0}\right)^{2}}-\mathrm{r}_{0}
$$

where $r_{0}$ is the radius of the standard sphere. Suppose the corresponding central angle of $\left(\mathrm{x}_{\mathrm{i}}, \mathrm{z}_{\mathrm{i}}\right)$ is . From Fig.5 we can get that it can be written as:

$$
\theta=2 \tan ^{-1}\left(\frac{\mathrm{X}_{\mathrm{i}}-\mathrm{X}_{0}}{\mathrm{z}_{\mathrm{i}}-\mathrm{z}_{0}}\right)
$$

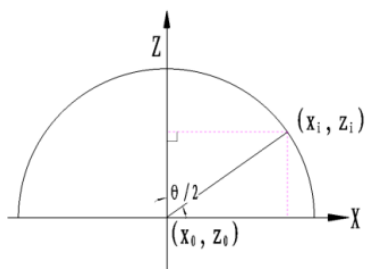

Fig. 5. The corresponding central angle of (xi, zi)

The result of the measured arc is shown in Fig.6 and $\Delta \mathrm{r}_{\mathrm{i}}$ is shown in Fig.7. From these figures, it is clear that the $\Delta r_{i}$ is symmetrical about the apogee of the arc.

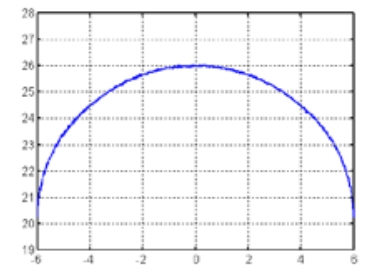

Fig. 6. The result of the measured arc

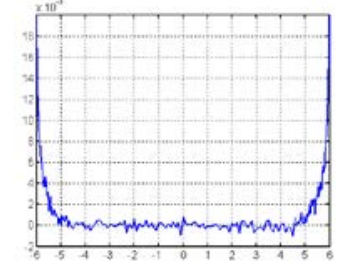

Fig. 7. The result of $\Delta r_{i}$
Replacing the $\mathrm{X}$ axis in Fig.7 with $\theta$, then we can get a result shown in Fig.8. It is obvious that the precision is higher than $10 \mu \mathrm{m}$ between $-45^{\circ}$ to $45^{\circ}$, and it will grow quickly when $\theta$ is over this range.

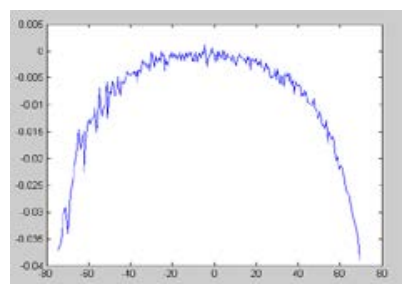

Fig. 8. The result of $\Delta r_{i}$ with $\theta$

\section{APPLICATION}

To compare the probes in focus, we measure the same standard sphere whose diameter is $30.005 \mathrm{~mm}$ with two probes and use the least-square method to fit the sphere [6].

Supposed $\mathrm{p}_{\mathrm{i}}\left(\mathrm{x}_{\mathrm{i}}, \mathrm{y}_{\mathrm{i}}, \mathrm{z}_{\mathrm{i}}\right)(\mathrm{i}=1,2, \cdots \mathrm{N})$ are the coordinates of $\mathrm{N}$ points on the sphere, the perfect equation can be written as:

$$
\left(\mathrm{x}-\mathrm{x}_{0}\right)^{2}+\left(\mathrm{y}-\mathrm{y}_{0}\right)^{2}+\left(\mathrm{z}-\mathrm{z}_{0}\right)^{2}=\mathrm{R}^{2}
$$

Where $\left(\mathrm{x}_{0}, \mathrm{y}_{0}, \mathrm{z}_{0}\right)$ is the coordinates of center of sphere, $\mathrm{R}$ is the radius. The above equation can be evolved as:

$$
\mathrm{x}^{2}+\mathrm{y}^{2}+\mathrm{z}^{2}-2\left(\mathrm{x}_{0} \mathrm{x}+\mathrm{y}_{0} \mathrm{y}+\mathrm{z}_{0} \mathrm{z}\right)+\left(\mathrm{x}_{0}^{2}+\mathrm{y}_{0}^{2}+\mathrm{z}_{0}^{2}-\mathrm{R}^{2}\right)=0
$$

Replace $\left(\mathrm{x}_{0}^{2}+\mathrm{y}_{0}^{2}+\mathrm{z}_{0}^{2}-\mathrm{R}^{2}\right)$ with $\mathrm{C}$, then according to the leastsquare method, the object function can be written as:

$$
\mathrm{F}\left(\mathrm{x}_{0}, \mathrm{y}_{0}, \mathrm{z}_{0}, \mathrm{C}\right)=\sum_{\mathrm{i}=1}^{\mathrm{N}}\left(\mathrm{x}_{\mathrm{i}}^{2}+\mathrm{y}_{\mathrm{i}}^{2}+\mathrm{z}_{\mathrm{i}}^{2}-2 \mathrm{x}_{0} \mathrm{x}_{\mathrm{i}}-2 \mathrm{y}_{0} \mathrm{y}_{\mathrm{i}}-2 \mathrm{z}_{0} \mathrm{z}_{\mathrm{i}}+\mathrm{C}^{2}\right)
$$

According to the extremal condition and Gauss method, the solution of the equation can be written as: 


$$
\left\{\begin{array}{c}
\mathrm{x}_{0}=\frac{\left(\mathrm{S}_{11} \mathrm{~S}_{33}-\mathrm{S}_{13} \mathrm{~S}_{23}\right)\left(\mathrm{S}_{24} \mathrm{~S}_{33}-\mathrm{S}_{23} \mathrm{~S}_{34}\right)-\mathrm{S}_{13} \mathrm{~S}_{22}}{\mathrm{~S}_{12}^{2}-\left(\mathrm{S}_{11} \mathrm{~S}_{33}-\mathrm{S}_{13}^{2}\right)\left(\mathrm{S}_{22} \mathrm{~S}_{33}-\mathrm{S}_{23}^{2}\right)} \\
\mathrm{y}_{0}=\frac{\left(\mathrm{S}_{11} \mathrm{~S}_{33}-\mathrm{S}_{13} \mathrm{~S}_{23}\right)\left(\mathrm{S}_{14} \mathrm{~S}_{33}-\mathrm{S}_{13} \mathrm{~S}_{34}\right)-\mathrm{S}_{11} \mathrm{~S}_{23}}{\mathrm{~S}_{12}^{2}-\left(\mathrm{S}_{11} \mathrm{~S}_{33}-\mathrm{S}_{13}^{2}\right)\left(\mathrm{S}_{22} \mathrm{~S}_{33}-\mathrm{S}_{23}^{2}\right)} \\
\mathrm{z}_{0}=\frac{\mathrm{S}_{34}-\mathrm{S}_{13} \mathrm{x}_{0}-\mathrm{S}_{23} \mathrm{y}_{0}}{\mathrm{~S}_{33}} \\
\mathrm{C}=\frac{1}{\mathrm{~N}}\left[2 \mathrm{x}_{0} \sum_{\mathrm{i}=1}^{\mathrm{N}} \mathrm{x}_{\mathrm{i}}+2 \mathrm{y}_{0} \sum_{\mathrm{i}=1}^{\mathrm{N}} \mathrm{y}_{\mathrm{i}}+2 \mathrm{z}_{0} \sum_{\mathrm{i}=1}^{\mathrm{N}} \mathrm{z}_{\mathrm{i}}-\sum_{\mathrm{i}=1}^{\mathrm{N}}\left(\mathrm{x}_{\mathrm{i}}^{2}+\mathrm{y}_{\mathrm{i}}^{2}+\mathrm{z}_{\mathrm{i}}^{2}\right)\right] \\
\mathrm{R}=\sqrt{\mathrm{x}_{0}^{2}+\mathrm{y}_{0}^{2}+\mathrm{z}_{0}^{2}-\mathrm{C}}
\end{array}\right.
$$

Where

$$
\left\{\begin{array}{l}
\mathrm{S}_{11}=2\left[\mathrm{~N} \sum_{\mathrm{i}=1}^{\mathrm{N}} \mathrm{x}_{\mathrm{i}}^{2}-\left(\sum_{\mathrm{i}=1}^{\mathrm{N}} \mathrm{x}_{\mathrm{i}}\right)^{2}\right] \\
\mathrm{S}_{12}=2\left[\mathrm{~N} \sum_{\mathrm{i}=1}^{\mathrm{N}} \mathrm{x}_{\mathrm{i}} \mathrm{y}_{\mathrm{i}}-\sum_{\mathrm{i}=1}^{\mathrm{N}} \mathrm{x}_{\mathrm{i}} \sum_{\mathrm{i}=1}^{\mathrm{N}} \mathrm{y}_{\mathrm{i}}\right] \\
\mathrm{S}_{13}=2\left[\mathrm{~N} \sum_{\mathrm{i}=1}^{\mathrm{N}} \mathrm{x}_{\mathrm{i}} \mathrm{z}_{\mathrm{i}}-\sum_{\mathrm{i}=1}^{\mathrm{N}} \mathrm{x}_{\mathrm{i}} \sum_{\mathrm{i}=1}^{\mathrm{N}} \mathrm{z}_{\mathrm{i}}\right] \\
\mathrm{S}_{14}=\mathrm{N} \sum_{\mathrm{i}=1}^{\mathrm{N}} \mathrm{x}_{\mathrm{i}}\left(\mathrm{x}_{\mathrm{i}}^{2}+\mathrm{y}_{\mathrm{i}}^{2}+\mathrm{z}_{\mathrm{i}}^{2}\right)-\sum_{\mathrm{i}=1}^{\mathrm{N}} \mathrm{x}_{\mathrm{i}} \sum_{\mathrm{i}=1}^{\mathrm{N}}\left(\mathrm{x}_{\mathrm{i}}^{2}+\mathrm{y}_{\mathrm{i}}^{2}+\mathrm{z}_{\mathrm{i}}^{2}\right) \\
\mathrm{S}_{23}=2\left[\mathrm{~N} \sum_{\mathrm{i}=1}^{\mathrm{N}} \mathrm{y}_{\mathrm{i}}^{2}-\left(\sum_{\mathrm{i}=1}^{\mathrm{N}} \mathrm{y}_{\mathrm{i}}\right)^{2} \mathrm{y}_{\mathrm{i}} \mathrm{z}_{\mathrm{i}}-\sum_{\mathrm{i}=1}^{\mathrm{N}} \mathrm{y}_{\mathrm{i}} \sum_{\mathrm{i}=1}^{\mathrm{N}} \mathrm{z}_{\mathrm{i}}\right] \\
\mathrm{S}_{34}=\mathrm{N} \sum_{\mathrm{i}=1}^{\mathrm{N}} \mathrm{z}_{\mathrm{i}}\left(\mathrm{x}_{\mathrm{i}}^{2}+\mathrm{y}_{\mathrm{i}}^{2}+\mathrm{z}_{\mathrm{i}}^{2}\right)-\sum_{\mathrm{i}=1}^{\mathrm{N}} \mathrm{z}_{\mathrm{i}}^{\mathrm{N}} \sum_{\mathrm{i}=1}^{\mathrm{N}}\left(\mathrm{x}_{\mathrm{i}}^{2}+\mathrm{y}_{\mathrm{i}}^{2}+\mathrm{z}_{\mathrm{i}}^{2}\right) \\
\mathrm{S}_{24}=\mathrm{N} \sum_{\mathrm{i}=1}^{\mathrm{N}} \mathrm{y}_{\mathrm{i}}\left(\mathrm{x}_{\mathrm{i}}^{2}+\mathrm{y}_{\mathrm{i}}^{2}+\mathrm{z}_{\mathrm{i}}^{2}\right)-\sum_{\mathrm{i}=1}^{\mathrm{N}} \mathrm{y}_{\mathrm{i}} \sum_{\mathrm{i}=1}^{\mathrm{N}}\left(\mathrm{x}_{\mathrm{i}}^{2}+\mathrm{y}_{\mathrm{i}}^{2}+\mathrm{z}_{\mathrm{i}}^{2}\right) \\
\left.\left.\sum_{\mathrm{N}}^{\mathrm{N}} \mathrm{z}_{\mathrm{i}}\right)^{2}\right]
\end{array}\right.
$$

The result is shown in Fig.9. It is clear that compared with laser triangulation, conoscopic holography probe can offer better precision and repeatability.

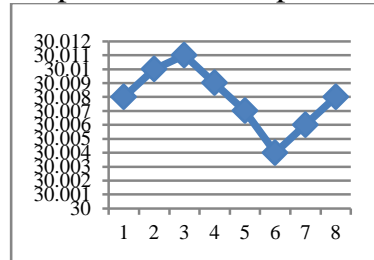

a) Laser triangulation

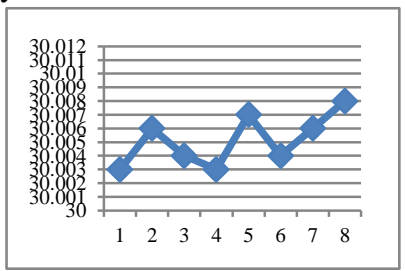

b) Conoscopic holography
Fig. 9. Standard sphere experiments (unit: $\mathrm{mm}$ )

\section{CONCLUSION}

In this paper, we analyzed the basic theory and characteristics of two kinds of probe respectively based on laser triangulation and conoscopic holography, compared the characteristics through measuring standard sphere fitted by the least square method.

According to the results, we can get the following conclusions:

(1) Probe based on laser triangulation can offer wide range and high sensitivity, but precision may be affected by angle change between optical axis and the surface to measure. Moreover, this measurement may occur speckle effect when the surface is rough and the positioning accuracy is not ideal for micro scale measurement.

(2) Probe based on conoscopic holography can offer high precision and linearity and keep better precision when the angle range between optical axis and the surface is between $-45^{\circ}$ to $45^{\circ}$. The diameter of the light is about $6 \mu \mathrm{m}$ but its range is narrow and the weight is higher.

(3) Compared these two kinds of probe, it is obvious that conoscopic holography probe can hold better precision (within $5 \mu \mathrm{m})$ and linearity $\mathrm{n}$ large-angle, and the diameter is smaller, so it is more suitable for measuring components with distinct curvature.

On the basis of all the above conclusions, we selected conoscopic holography probe to measure the typical characteristics of aero-engine components. And according to the characteristics of conoprobe, it was used for dedicated measuring on important complex components on aero-engine such as small vane and nozzle. The application is coming true now and the research on dedicated measurement on small vane and nozzle will be go on as it is an urgent requirement for internal aero-engine.

\section{REFERENCES}

[1] Ding Han, Zhu Limin, Xiong Zhenhua. Rapid Measure and Model on Complex Curve and RP and NC Techonology Base on points[J]. Chinese Journal of Mechanical Engineering, 2003, 39(11), pp: 28-37. (In Chinese).

[2] Gao Xiang. Research on the Effects of Polarized Light Interference on Detecting Geometrical Morphology [J]. Journal of Optics. 2002, 22(4), pp: 452 455. (In Chinese).

[3] Wang Xiaojia, Gao Jun, Wang Lei. Summarize on Laser Triangulation[J]. Chinese Journal of Scientific Instrument. 2004, 25(z3). (In Chinese).

[4] Mugnier L M, Sirat G Y and Charlot D. Conoscopic Holography: TwoDimensional Numerical Reconstructions[J]. Optics Letters, 1993, 18:66 68

[5] Mugnier L M. Conoscopic Holography: Toward three-Dimensional Reconstructions of Opaque Objects[J]. Applied Optics, 1995, 34(8): 1363 1371

[6] Fei Zhigen. Key Technology Research on The Target Assembly Parameters Detection System[D]. Xi'an Jiaotong University. 2011(11). (In Chinese). 